\title{
REVIEW
}

\section{Exercise induced Leg Pain due to Vascular Compression Syndrome}




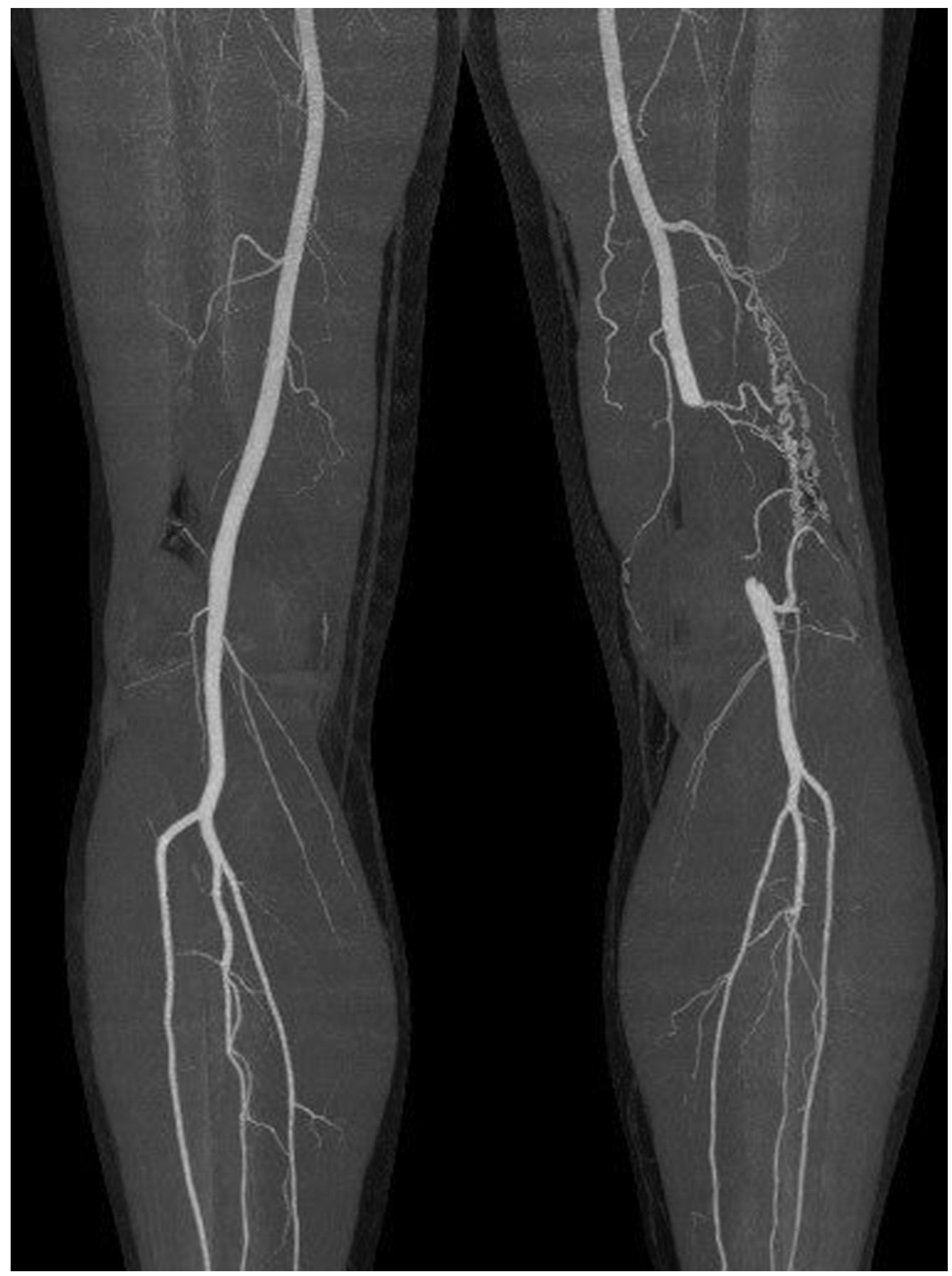




\title{
Gaehwiler Roman $^{1,2}$, Hirschmueller Anja ${ }^{3,4}$, Grumann Thorsten $^{5}$, Weber Viktoria ${ }^{1}$, Isaak Andrej $^{6}$, Thalhammer Christoph ${ }^{1}$
}

${ }^{1}$ Cantonal Hospital Aarau, University Hospital, Department of Angiology, Switzerland

${ }^{2}$ Danube University Krems, Department of Health \& Medicine, Austria

${ }^{3}$ ALTIUS Swiss Sportmed Center AG, Rheinfelden AG, Switzerland

${ }^{4}$ University Hospital Freiburg, Department of Orthopedic Surgery \& Traumatology, Germany

${ }^{5}$ Cantonal Hospital Lucerne, Department of Angiology, Switzerland

${ }^{6}$ Cantonal Hospital Aarau, Department of Vascular Surgery, Switzerland

\begin{abstract}
Within a sports medicine setting vascular pathologies of the legs represent a rare entity and are often associated with a significant delay of diagnosis and treatment. Nevertheless, timely detection is crucial when it comes to management of athletes. Three types of vascular compression syndromes are going to be summarized within this review. Therefore, adductor's canal (or Hunter's canal) represents an external compression of the superficial artery located in the middle third of the thigh causing exercise-induced calf pain and numbness of toes. Popliteal artery entrapment syndrome reflects another vascular compression syndrome which arises through its anatomic demarcation by the medial head of the gastrocnemius (inferomedial), the lateral head of the gastroncnemius and plantaris (inferolateral), semitendinosus and semimembranosus (superomedial), and biceps femoris (superolateral) muscles. Finally, cystic adventitial disease is located in the popliteal artery in up to $80.5 \%$ of the cases and may cause narrowing of the vessel lumen due to certain processes within the vascular wall. However, it appears to affect athletes and nonathletic people likewise.
\end{abstract}

\section{Zusammenfassung}

In der sportmedizinischen Praxis sind vaskuläre Kompressionssyndrome der unteren Extremitäten eine Seltenheit. Trotzdem ist deren zeitnahe und korrekte Diagnose für den betroffenen Athleten von zentraler Bedeutung. Konsekutiv werden im Rahmen dieser Übersichtsarbeit die wichtigsten drei Syndrome zusammengefasst, welche sich klinisch im Sinne belastungsinduzierter digitaler Parästhesien oder einer Unterschenkel-Claudicatio manifestieren können. Dabei ist das Adduktorenkanal-Syndrom durch eine externe Kompression der A. femoralis superficialis im mittleren Oberschenkel-Drittel gekennzeichnet. Das popliteale Entrapment ist durch eine anatomische Engstelle bedingt, welche auf Variationen der Gastrocnemius-Muskulatur in Relation zum M. biceps femoris beziehungsweise der Mm. semitendinosus/membranosus gründet. Schlussendlich können Mikroläsionen in der Kniegelenkkapsel auch die Entstehung einer zystischen Adventitia-Degeneration im Bereich der A. poplitea begünstigen. 


\section{Introduction}

Vascular medicine (or angiology) is inexistent in sports medicine. Nevertheless, vascular pathologies are often associated with a significant delay of diagnosis and treatment that might be crucial when it comes to sports medical care of competitive athletes. Peripheral vessels are subject to specific shear stresses during athletic performance due to localized muscular hypertrophy and increased cardiac output. There are various anatomic sites of constriction in the leg which predispose for compression syndromes. Although, clinical examination in the resting state may often reveal unremarkable, vascular examination contains inspection and palpation of the affected limb in view of findings such as pallor, weak or absent pulses, and prolonged capillary refill.[1,2]

In this review, we are going to describe three entities of non-traumatic lower leg pain due to vascular compression and provide further information refer to epidemiology, sports at risk, pathophysiology, diagnosis, and therapeutic management.

\section{Adductor's Canal Syndrome}

\section{Epidemiology / Sports at Risk}

Adductor's canal (or Hunter's canal) syndrome was first described by Palma in 1950 when he noted an external compression of the superficial femoral artery located in the middle third of the thigh.[3] Male gender is predominantly affected at a mean age of 45 years.[4] Sports such as running, skiing or soccer are at risk for the development of this rare entity.[4] It might be noteworthy that female involvement with reference to adductor's canal syndrome is infrequent.[5] Palma substantiated this observation by arguing that female patients display a more oblique femur position and a larger adductor canal.[6]

\section{Pathophysiology - vascular compression by anomalous musculotendinous band}

The adductor's canal represents an aponeurotic tunnel containing the femoral vessels (artery and vein) as well as the saphenous nerve. This structure is bounded by the vastus medialis (anterolaterally), the adductor magnus and longus (posteriorly), and the sartorius muscle (medially).[5,7] External arterial compression may originate from an embryologic anomalous musculotendinous band, which arises from the adductor magnus muscle and/or a hypertrophied vastus medialis.[5,8] De Oliveira et al. underpin this suggestion, and simultaneously propose a standard age-related modification of connective tissue (increase in transversal fiber density and type III collagen in adults) in the adductor-canal, which prevents the vessels from sliding freely during movements.[9] 


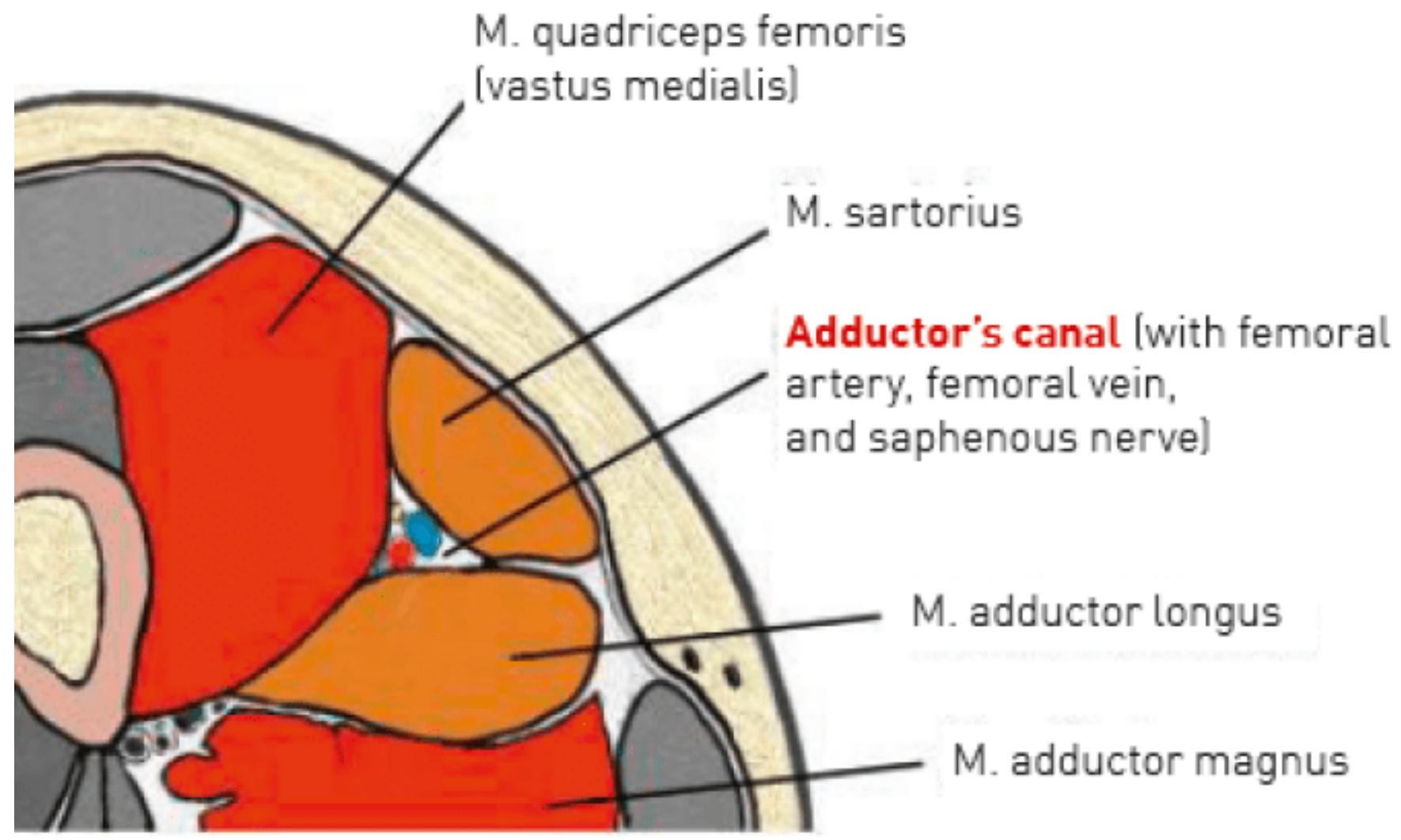

Figure 1: Transversal view of proximal thigh with hypertrophied muscles (red) and anatomic features of adductor's canal. 


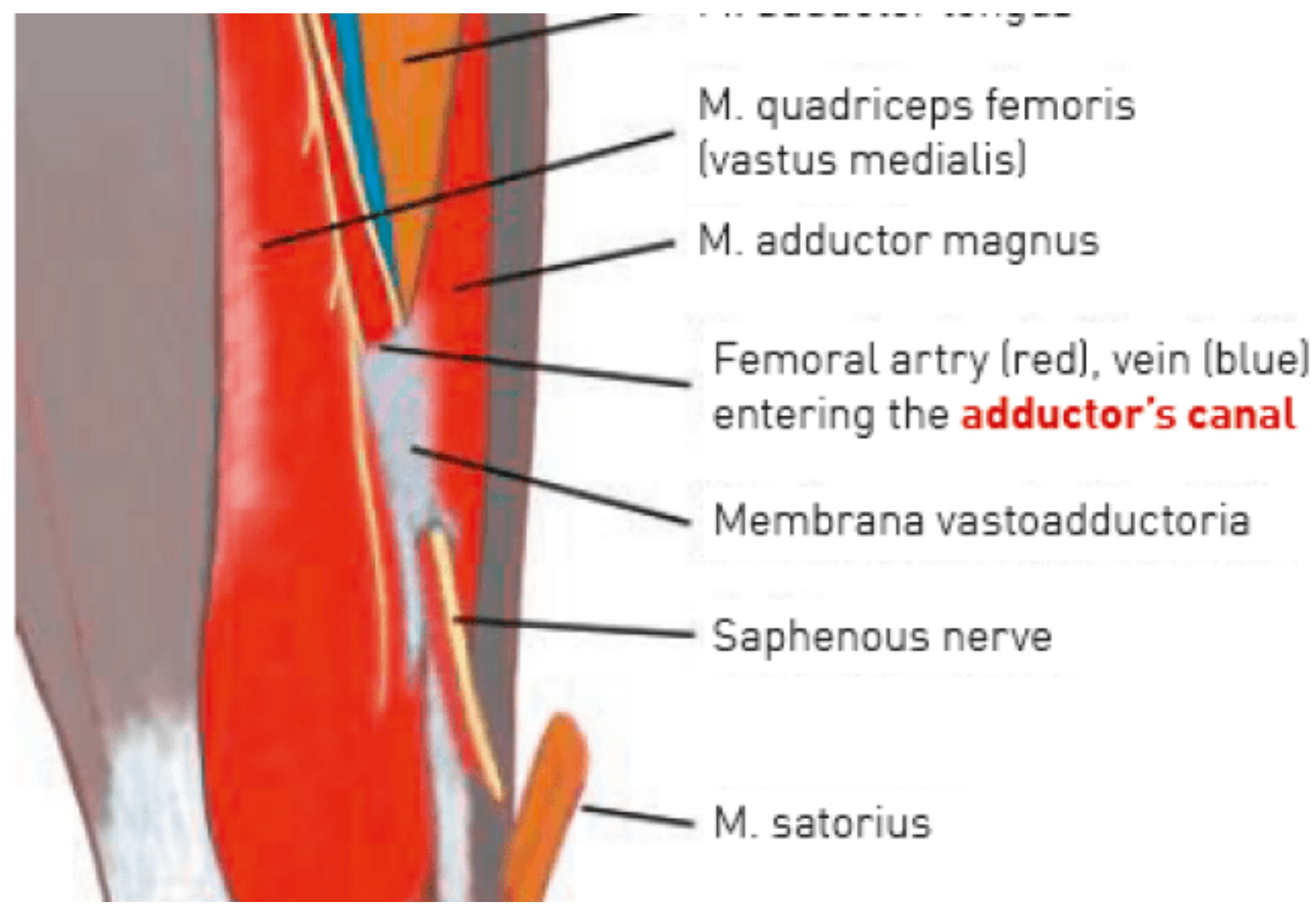

Figure 2: Frontal view of distal third of the thigh at the level of adductor's hiatus with vastoadductor membrane.

\section{Diagnostics}

Usually, athletes suffering from adductor's canal syndrome complain about exercise-induced calf pain and paresthesia. In particular, numbness of toes seems to be a relevant symptom.[7] Concerning neurological differential diagnosis the sports medical physician may also keep in mind saphenous nerve entrapment at the adductor canal which could become symptomatic as anterior knee pain.[10] In case of pain at rest and pulselessness also thrombotic vessel occlusion has to be taken into consideration. Accordingly, exercise ABPI-studies, duplex ultrasonography, and angiography might be of assistance in establishing the diagnosis. Surrounding soft tissue may be evaluated by MRI.[11]

\section{Therapy}

Surgical treatment of adductor's canal syndrome is unavoidable. Hence, resection of abnormal musculotendinous bands plus vein patch angioplasty (or bypass of the destructed artery segment) represents standard care in these patients.[7] According to Ehsan et al. short-term results are good and most athletes are capable to return to previous performances.[8] Regrettably, long-term data are still scarce. 


\section{Popliteal Artery Entrapment}

\section{Epidemiology / Sports at Risk}

In 1879 a medical student from the University of Edinburgh published a "note on a variation in the course of the popliteal artery" and described the anatomical foundation of popliteal artery entrapment syndrome (PAES).[12] In the meantime, PAES became a rare but crucial vascular cause for chronic lower leg pain in physically active people with a documented prevalence of $0.2 \%$.[13] Usually, cases are unilateral, but almost $25 \%$ of patients experience bilateral involvement.[14] Young active men seem to be affected predominantly, with a male to female ratio of 15:1.[15] Meanwhile, popliteal entrapment without anatomic predisposition, also known as "functional" popliteal artery entrapment syndrome (FPAES), has been identified mostly in young athletic women (female proportion of 56\%, mean age 26.9 years) with bilateral symptoms in 75\% of cases.[16,17] Even 7-14 year old children may experience intermittent claudication due to popliteal entrapment.[18,19] Therefore, potential context with disturbed embryological development of the popliteal fossa is debatable. Nevertheless, within a systematic review mean age of symptom onset is reported to be at 32 years (range, 20.7-41 years).[20]

Sports at risk of provoking popliteal entrapment include all kinds of disciplines such as running $(\approx 47 \%)$, soccer $(\approx 25 \%)$, water sports ( $\approx 8 \%)$, basketball ( $\approx 6 \%)$, football, skiing, biking, hockey, and rowing.[21]

\section{Pathophysiology - vascular compression by calf musculature}

PAES is defined as a congenital fibromuscular anomaly in the popliteal fossa (posterior knee-area) inducing extrinsic compression and displacement of the neurovascular bundle containing the tibial nerve, popliteal artery, and vein.[7] The constriction phenomenon arises through its anatomic demarcation by the medial head of the gastrocnemius (inferomedial), the lateral head of the gastrocnemius and plantaris (inferolateral), semitendinosus and semimembranosus (superomedial), and biceps femoris (superolateral) muscles.[22] In the course of embryological evolution this anatomic region appears to be a subject of "competition of space" between migrating muscle groups and the primitive neurovascular bundle.[23] Consequently, most common anomalies constitute of incomplete or delayed migration of the medial head of gastrocnemius muscle which triggers abnormal lateral displacement of muscle insertion.[24] Nevertheless, entrapment due to anatomical variants needs to be distinguished from functional artery entrapment where abnormal popliteal fossa anatomy is absent.[25] According to the Popliteal Vascular Entrapment Forum consensus classification system Di Marzo and Cavallaro nominated 6 types of popliteal vessel entrapments.[26] 
Table 1: Types of popliteal vascular entrapment (adapted by Di Marzo and Cavallaro [26]

\begin{tabular}{|c|c|c|}
\hline Type & Anatomic abnormality & Position of Popliteal Artery \\
\hline Type I & $\begin{array}{l}\text { Popliteal artery proceeding medially in relation to the medial head of } \\
\text { gastrocnemius }\end{array}$ & Medial displacement \\
\hline Type II & $\begin{array}{l}\text { Abnormal medial head of gastrocnemius with insertion laterally on } \\
\text { the distal femur }\end{array}$ & Medial displacement \\
\hline Type III & $\begin{array}{l}\text { Aberrant accessory slip arising from the medial head of the } \\
\text { gastrocnemius muscle and embracing popliteal artery }\end{array}$ & Normal position \\
\hline Type IV & $\begin{array}{l}\text { Popliteal artery passing below popliteus muscle or fibrous bands } \\
\text { emerging from popliteus }\end{array}$ & Normal position \\
\hline Type V & Any form of type I-IV causing primarily venous entrapment & Normal position \\
\hline Type VI/F & Functional entrapment (normal popliteal fossa anatomy) & \\
\hline
\end{tabular}

Repetitive micro trauma to these vessel segments may cause stenotic artery degeneration, poststenotic dilatation, aneurysm formation, or complete artery occlusion.[20,27] Obviously, the popliteal artery underlies certain shear stress forces due to significant changes in geometry during knee flexion and tethering by genicular arteries, the adductor hiatus or the soleus arch.[28,29] Concerning the latter, Rignault et al. suggested the entity of "functional" popliteal entrapment syndrome (type VI) by performing dynamic angiographies in the sustained plantar flexion.[25] Therefore, the musculotendinous attachment of the soleus is located on the medial aspect of the tibia right below the knee joint and creates an area of potential neurovascular compression named "soleal sling". Noteworthy that the functional participation of soleus muscle with regard to plantar flexion of the foot represents $40 \%$ (gastrocnemius $33 \%$, foot-flexors such as digitorum/hallucis longus 27\%).[30] Furthermore, relevant popliteal artery entrapment may even be caused aberrant plantaris muscle.[31] Nonetheless, temporary occlusion of popliteal artery during maximal plantar flexion (combined with leg extension) is a common finding in 53\% of asymptomatic people.[32]

\section{Diagnostics}

Clinical presentation of popliteal entrapment is manifold. Most patients complain about calf muscle cramping, rapid limb fatigue, as well as occasional paresthesia on the plantar surface of the foot while running or jumping.[33] According to a systematic review by Sinha et al., median duration of symptoms before diagnosis accounts for 12 months. Paradoxically, there appears to be no relationship between the duration of symptoms and emergence of irreversible arterial damage (occlusion, poststenotic dilatation, or aneurysm formation).[20] Other than in peripheral vascular disease, where the pain fades away with rest, the pain in PAES may linger despite pausing the activity.[22]

Elaborate clinical assessment and exercise testing with ankle-brachial pressure (ABI) measurement remains the primary diagnostic step. Thus, limbs with PAES display a significant ABI response to treadmill exertion with a mean numeric ABI decrease of -0.18 (reduction of $16 \%$ from baseline) in the affected limb. 
This clearly distinguishes symptomatic from asymptomatic limbs that have no relevant change in $\mathrm{ABI}$ one minute after walking on an incline or running (ABI decrease of -0.02).[34] Remarkably, Brown et al. observed also that running without incline elicited a more robust ABI response than did inclined walking. Subsequently, this leads to the reversed conclusion that running is more likely to trigger popliteal artery compression.[34] However, ABI decrease does not correlate with the type of popliteal entrapment.[35] In summary, provocation Doppler sonography in combination with ABI-measurement reveals an estimated mean sensitivity of $90 \%$ (median 100\%, range 50-100\%).[20] Although, MRI is the current gold standard to identify popliteal fossa anatomy at rest, accurate examination while maintaining plantar flection remains challenging. Therefore, magnetic resonance imaging might assist identification of various gastrocnemius anomalies and concurrently support surgical treatment strategy.[36] Furthermore, provocation CTangiography and arteriography can be used to confirm the diagnosis with a mean sensitivity-estimate of 97-100\%.[20] In contrast, photoplethysmography (optically obtained measurement of the volume and vascular perfusion in various organs) is most sensitive for FPAES (mean estimate of sensitivity 100\%, median 100\%).[7,20]

\section{Therapy}

Surgical treatment of PAES intends resection of the popliteal artery from the constricting musculotendinous tissue as well as autogenous saphenous vein patch angioplasty. If intimal vessel damage is present also thrombectomy might be indicated.[37] Regarding the literature, open surgery is preferred compared to endovascular approaches (e.g. stenting).[38] In view of outcome analysis, successful resolution of symptoms could be reached with a median value of 77\% (range, 70-100\%).[20] Finally, graft patency after surgery remains very good with $90 \%$ exceeding 5-year survival rate.[39] 


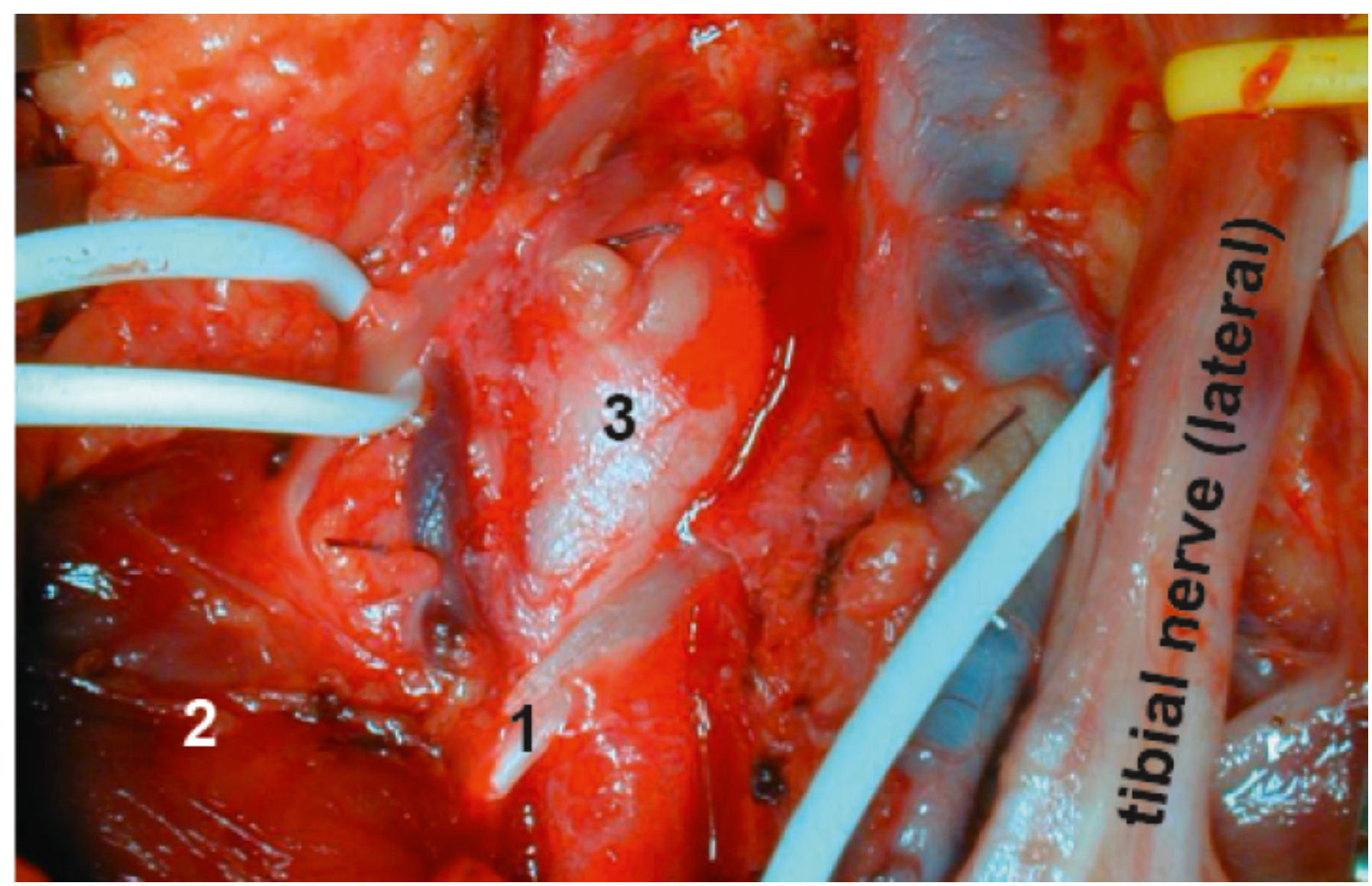

Figure 3: Intraoperative anatomy of popliteal fossa in type III.

Anatomy of popliteal fossa in a patient with popliteal entrapment (type III) and aberrant accessory slip (1) arising from the medial head of the gastrocnemius muscle (2), and associated pre-stenotic popliteal artery aneurysm (3).

With reference to functional PAES surgical decompression strategies tended to acknowledge the superiority of posterior approach in order to expose popliteal fossa anatomy rather than medial approach which was performed only when an arterial bypass procedure was anticipated.[20] In various studies prophylactic four compartment fasciotomies were also considered.[24] Concerning the management of PAES and FPAES, the evidence level is poor. According to Turnipseed et al. postoperative management of FPAES included crutches for 3-4 days and starting of non-impact aerobic rehabilitation at one week after surgery. In the absence of any complications within non-impact aerobic conditioning, patients were enrolled in an injured runners program at 4-6 weeks post-operation.[16] With regard to the outcome $78 \%$ of competitive athletes were able to return to previous performances, whereas return to recreational level seems to be possible for almost everybody.[17]

\section{Cystic Adventitial Disease}

\section{Epidemiology / Sports at Risk}

This entity was first described in 1947 by Atkins and Key [40] and represents a very rare disease revealing 
a prevalence of 1:2000 and accounting for $0.1 \%$ of vascular illnesses with a male-to-female-ratio of 4:1. Involvement of the popliteal artery accounts for $80.5 \%$ of the cases.[40,41] Cystic adventitial disease appears to affect athletes and non-athletic people likewise. Nonetheless, with reference to the demands of sport or heavy manual leg work this entity might become symptomatic earlier in athletes than in those performing a sedentary lifestyle.[42] Thus, cystic adventitial disease in the popliteal artery may occur in various disciplines such as running, soccer or triathlon.[43]

\section{Pathophysiology - narrowing of the vessel lumen due to processes in the vascular wall}

Adventitial cysts may present as eccentric, slowly growing soft tissue masses in the popliteal fossa with a "strings of pearls"-like appearance in magnetic resonance imaging.[43] The composition of the cysts display mucoproteins, mucopolysaccharides, hyaluronic acid and hydroxyproline.[44] The exact etiology of adventitial cystic disease remains unknown. According to one of the largest systematic reviews (including 724 patients) by Desy and Spinner the "articular synovial theory" might fit best. Therefore, the authors believe that "adventitial cyst formation begins with a capsular rent or defect that leads to the tracking of synovial fluid along a vascular articular branch”.[41] In accordance to this, a joint connection could be identified in 122 (17\%) of their scrutinized cases.[41]

\section{Diagnostics}

Symptoms of adventitial cystic disease are unspecific, but in $81 \%$ associated with intermittent exertional claudication or occasionally with a growing mass in the popliteal fossa similar to Baker's cyst.[41,43] Unlike the rapid easing of calf pain due to atherosclerotic stenosis, vessel narrowing based on adventitial cystic disease might cause prolonged post exercise recovery time of approximately 10-20 minutes.[45] Consequently, clinical examination may reveal diminished pedal pulses while flexing the knee, a finding also known as "Ishikawa-sign”.[46] Fast available and cost-effective ultrasound may just reveal a hypoechoic cyst posterior to the popliteal artery.[43] However, magnetic resonance tomography is the noninvasive modality of choice in order to identify adventitial cystic disease, as well as a possible connection to the knee joint.[41] Supplementary, magnetic resonance angiography may visualize involvement of the genicular arteries which might serve as an important information to the vascular surgeon.[47] 


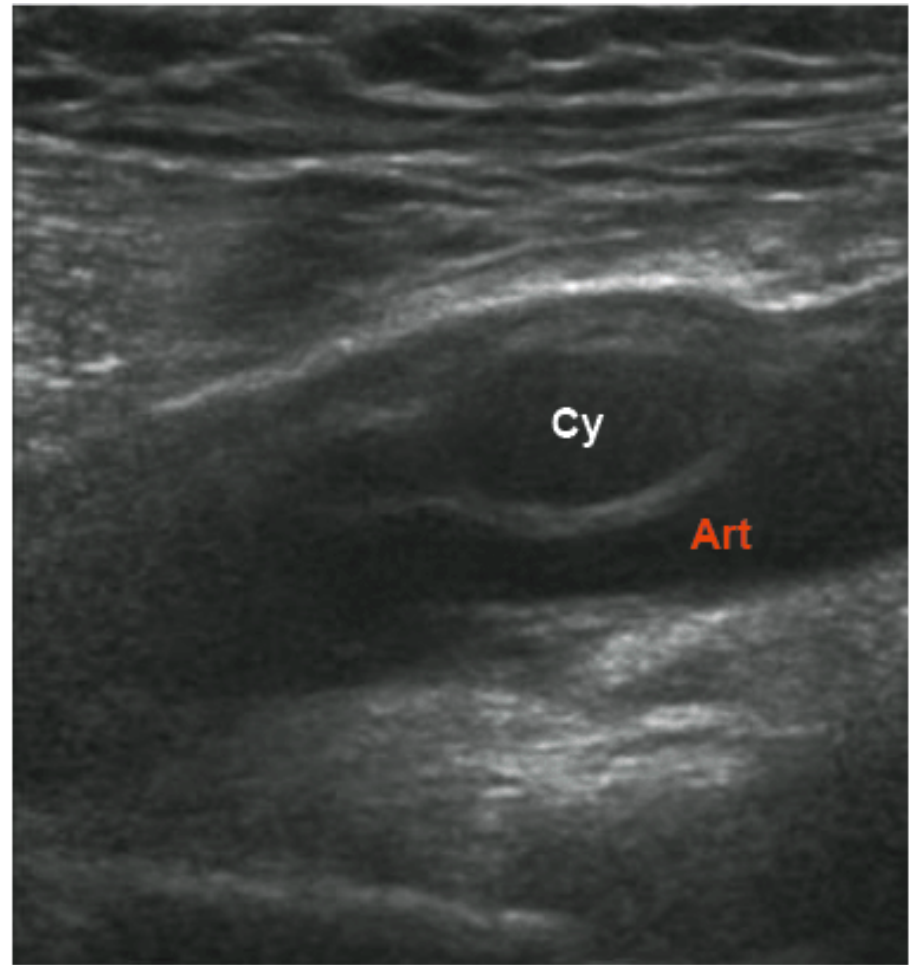

B-mode sonography (longitudinal view) with hypoechoic cyst [Cy] posterior to the popliteal artery [Art]

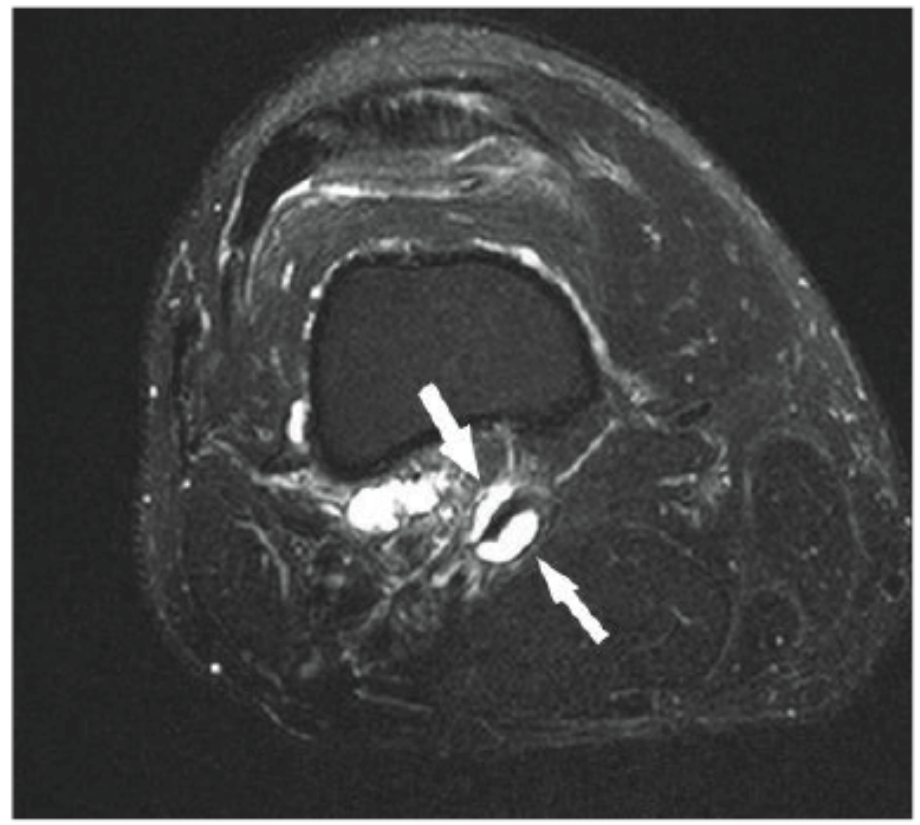

MRI [coronary view] which demonstrates hyperintens cyst formation posterior to the knee [white arrows]

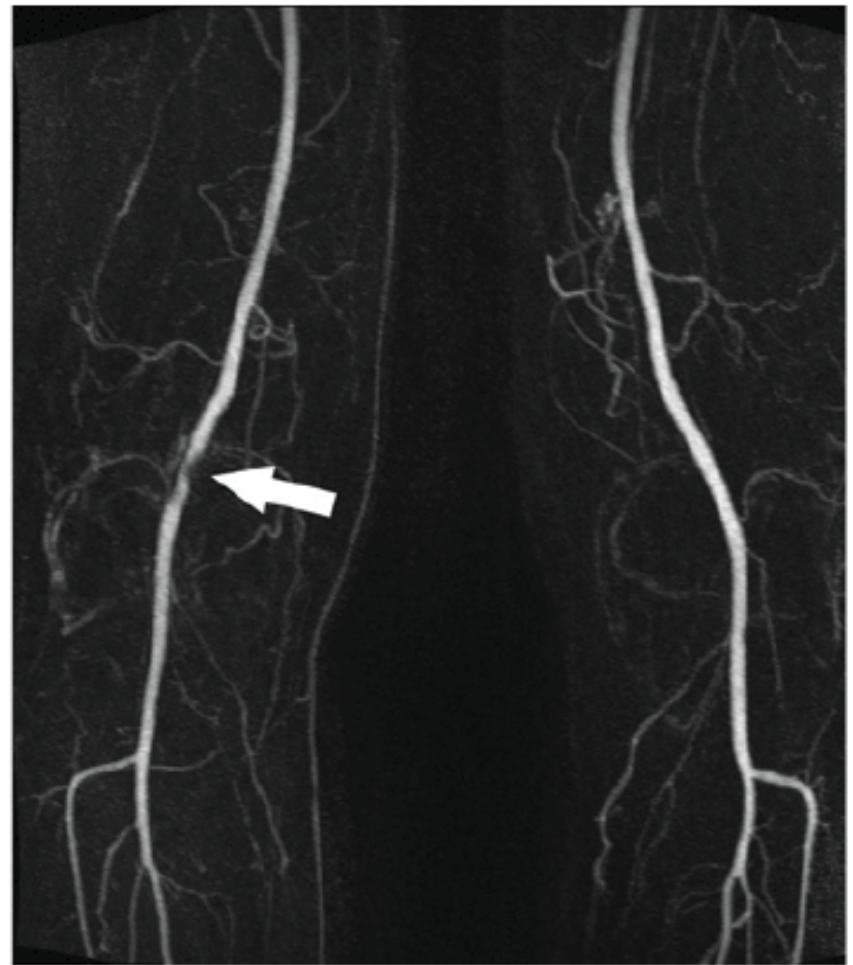

MR-angiography with proof of vascular compression of right popliteal artery [arrow]

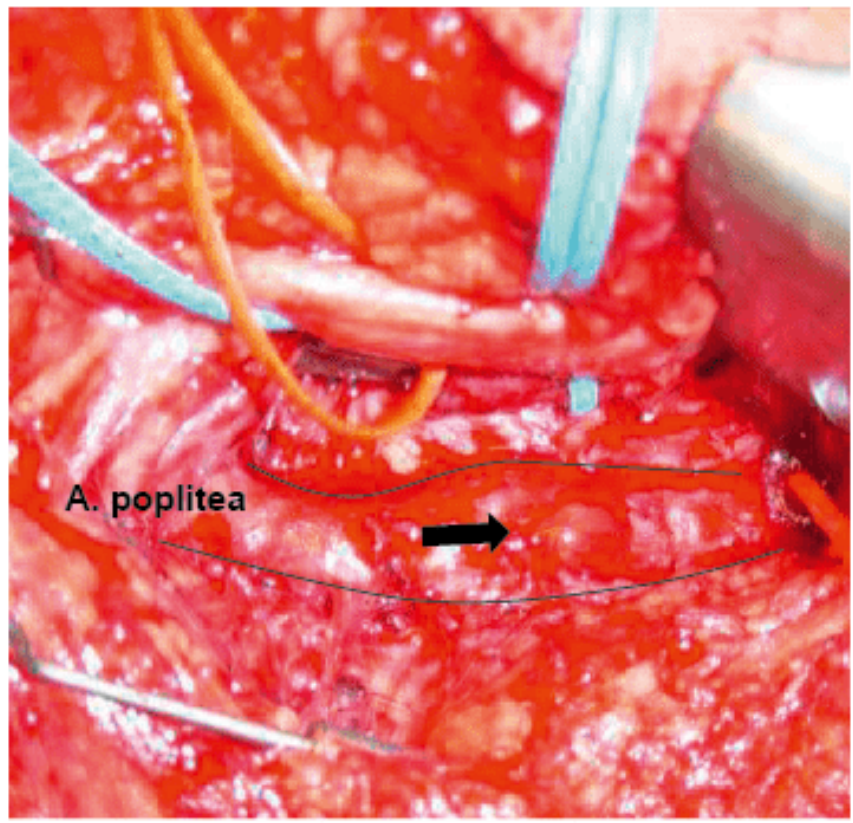

Intraoperative visualization of popliteal fossa with cystic adventitial degeneration (arrow) along the popliteal artery [lines $=$ demarcation of $\mathrm{A}$. poplitea)

Figure 4: Diagnostic images of a 59-year old patient with cystic adventitial disease.

\section{Therapy}

Percutaneous surgery (aspiration or angioplasty) represented a risk factor for cyst recurrence (odds ratio, 
13.7; 95\% confidence interval, 6.5-29.0; p-value < 0.0001).[41] Therefore, common open surgical options are favoring cyst resection and vessel reconstruction with saphenous vein autograft.[48] Even though, failure rate after cyst excision and bypass surgery account for 6.8\%.[48]

\section{Differential diagnosis of non-traumatic exercise induced leg pain}

Admittedly, identification and correct diagnosis of non-traumatic exercise induced leg pain represents a major challenge and is often a result of teamwork and interdisciplinary thinking. In this respect, the crucial point with regard to vascular compression syndromes is the knowledge about their existence, as well as their timely detection. Sports medicine is an interdisciplinary field. Correspondingly, symptoms and clinical findings in patients suffering from non-traumatic lower leg pain may confront the physician with a large amount of possible differential diagnoses. Vascular pathologies in the athlete may trigger symptoms similar to musculoskeletal or nervous diseases summarized in table 2 .

Table 2: Etiology of non-traumatic exercise induced leg pain.

\begin{tabular}{|c|c|c|}
\hline Vascular & Musculoskeletal & Nervous \\
\hline $\begin{array}{l}\text { External vascular compression: } \\
\text { Arteries: } \\
\text { Adductor-canal syndrome } \\
\text { Popliteal entrapment } \\
\text { Cystic adventitial disease } \\
\text { Veins: } \\
\text { May-Thurner Syndrome } \\
\text { Vessel wall processes: } \\
\text { Atherosclerotic stenosis } \\
\text { Endofibrosis of iliac artery } \\
\text { Endoluminal processes: } \\
\text { Thromboembolic events in veins or } \\
\text { arteries }\end{array}$ & $\begin{array}{l}\text { Overuse syndromes: } \\
\text { Tenosynovitis, tendinopathies le.g. } \\
\text { achilles tendon], stress fractures, } \\
\text { medial tibial periostalgia, sacroiliac } \\
\text { dysfunction } \\
\text { Myopathies: } \\
\text { Metabolic, inflammatory, or neoplastic } \\
\text { myopathies } \\
\text { Further causes: } \\
\text { Chronic exertional compartment } \\
\text { syndrome }\end{array}$ & $\begin{array}{l}\text { Nerve entrapment: } \\
\text { Neuropathy of saphenous, tibial or } \\
\text { peroneal nerve } \\
\text { Neurogenic claudication: } \\
\text { S1-Radiculopathy } \\
\text { Further Causes: } \\
\text { Inflammatory, infectious, metabolic, } \\
\text { neuroplastic, paraneoplastic, toxic, } \\
\text { inherited or degenerative }\end{array}$ \\
\hline
\end{tabular}

Considering external vascular compression syndromes, also venous compromise has to be taken into account. Therefore, May-Thurner (or Cockett's) syndrome is an important differential diagnosis for venous congestion or left-sided deep vein thrombosis in the leg. In the course of an autopsy series in 1957 May and Thurner described that $22 \%$ of their patients displayed signs of sinistral common iliac vein compression located at the crossover of the right common iliac artery.[49] Moreover, approximately $50 \%$ of patients suffering from deep vein thrombosis in the left lower extremity reveal compression of the left iliac vein.[50] 


\section{Conclusion}

Exercise-induced leg pain represents an intersection of disciplines such as vascular medicine, orthopedic surgery and neurology. Several anatomic locations predetermine for vascular compression syndromes due to excessive hemodynamic and biomechanical stress during certain movement patterns. Thus, adductor canal syndrome, popliteal entrapment syndrome, and cystic adventitial disease are rare, but important in sports medical practice.

\section{Practical implications}

- Vascular examination contains inspection and palpation of the affected limb in view of findings such as pallor, weak or absent pulses, and prolonged capillary refill.

- Adductor's canal (or Hunter's canal) represents an external compression of the superficial artery located in the middle third of the thigh causing exercise-induced calf pain and numbness of toes.

- Popliteal artery entrapment syndrome arises through its anatomic demarcation by the medial head of the gastrocnemius (inferomedial), the lateral head of the gastroncnemius and plantaris (inferolateral), semitendinosus and semimembranosus (superomedial), and biceps femoris (superolateral) muscles.

- Cystic adventitial disease is located in the popliteal artery in up to $80.5 \%$ of the cases and appears to affect athletes and non-athletic people likewise.

\section{Conflict of interest}

None declared.

\section{Korrespondenzadresse}

Dr. med. Roman Gähwiler

Assistenzarzt

Klinik für Angiologie

Kantonsspital Aarau

Tellstrasse

CH-5001 Aarau

Telefon 0628384702

E-Mail: Roman.Gaehwiler@ksa.ch

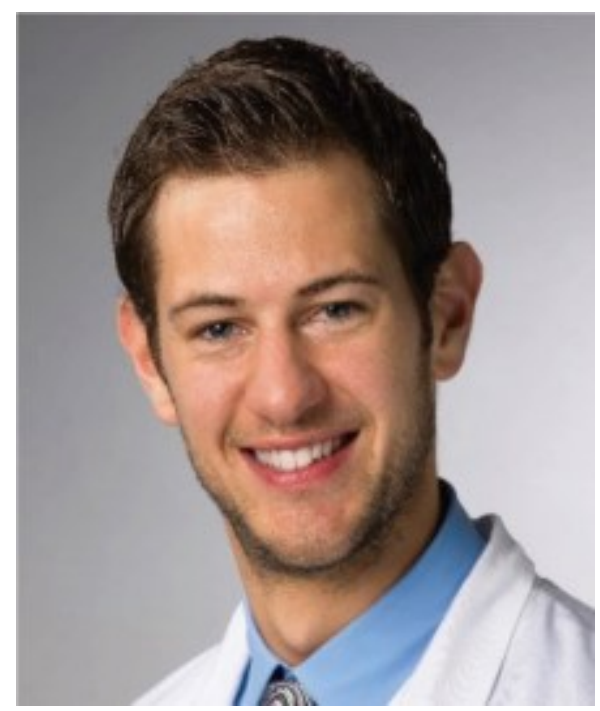

\section{References}

1. Arko FR, Harris EJ, Zarins CK, Olcott C. Vascular complications in high-performance athletes. J Vasc 
Surg. 2001;33(5):935-42.

2. Brearley S. Acute leg ischaemia. BMJ. 2013;346:f2681.

3. PALMA EC. [Stenosing arteriopathies of the lower extremity; Hunter's canal and third abductor ring syndrome]. Bol Trab Acad Argent Cir. 1950;34(21):771-87.

4. Sapienza P, Tartaglia E, Venturini L, Gallo P, di Marzo L. Adductor canal compression syndrome: a forgotten disease. Ann Ital Chir. 2014;85(ePub).

5. Zhou Y, Ryer EJ, Garvin RP, Irvan JL, Elmore JR. Adductor canal compression syndrome in an 18-yearold female patient leading to acute critical limb ischemia: A case report. Int J Surg Case Rep. 2017;37:113-8.

6. PALMA EC. Stenosed arteriopathy of the Hunter canal and loop of the adductor magnus. Am J Surg. 1952;83(6):723-33.

7. Akuthota V, Herring SA. Nerve and Vascular Injuries in Sports Medicine. Dordrecht, Heidelberg, London, New York: Springer; 2009.

8. Ehsan O, Darwish A, Edmundson C, Mills V, Al-Khaffaf H. Non-traumatic lower limb vascular complications in endurance athletes. Review of literature. Eur J Vasc Endovasc Surg. 2004;28(1):1-8.

9. de Oliveira F, de Vasconcellos Fontes RB, da Silva Baptista J, Mayer WP, de Campos Boldrini S, Liberti EA. The connective tissue of the adductor canal - a morphological study in fetal and adult specimens. J Anat. 2009;214(3):388-95.

10. Romanoff ME, Cory PC, Kalenak A, Keyser GC, Marshall WK. Saphenous nerve entrapment at the adductor canal. Am J Sports Med. 1989;17(4):478-81.

11. Perlowski AA, Jaff MR. Vascular disorders in athletes. Vasc Med. 2010;15(6):469-79.

12. Stuart TP. Note on a Variation in the Course of the Popliteal Artery. J Anat Physiol. 1879;13(Pt 2):162.

13. Bouhoutsos J, Daskalakis E. Muscular abnormalities affecting the popliteal vessels. Br J Surg. 1981;68(7):501-6.

14. Stager A, Clement D. Popliteal artery entrapment syndrome. Sports Med. 1999;28(1):61-70.

15. Mark LK, Kiselow MC, Wagner M, Goodman JJ. Popliteal artery entrapment syndrome. JAMA. 1978;240(5):465-6.

16. Turnipseed WD. Functional popliteal artery entrapment syndrome: A poorly understood and often missed diagnosis that is frequently mistreated. J Vasc Surg. 2009;49(5):1189-95.

17. Lavingia KS, Dua A, Rothenberg KA, Fredericson M, Lee JT. Surgical management of functional popliteal entrapment syndrome in athletes. J Vasc Surg. 2019;70(5):1555-62.

18. Bernheim JW, Hanson J, Hansen J, Faries P, Kilaru S, Winchester P, et al. Acute lower extremity ischemia in a 7-year-old boy: an unusual case of popliteal entrapment syndrome. J Vasc Surg. 2004;39(6):1340-3.

19. Molinaro V, Pagliasso E, Varetto G, Castagno C, Gibello L, Zandrino F, et al. Popliteal artery entrapment syndrome in a young girl: case report of a rare finding. Ann Vasc Surg. 2012;26(4):572.e5-9.

20. Sinha S, Houghton J, Holt PJ, Thompson MM, Loftus IM, Hinchliffe RJ. Popliteal entrapment syndrome. J Vasc Surg. 2012;55(1):252-62.e30.

21. Delgado Daza R, Moga Donadeu LL, Muncunill Gil J, Mañosa Bonamich J, Vidal Conde V. [Popliteal artery entrapment syndrome in 3 young athletes]. Angiologia. 1993;45(3):99-102.

22. Saa L, Firouzbakht PK, Otahbachi M. A Case of Overlooked Popliteal Artery Entrapment Syndrome. Cureus. 2019;11(3):e4252.

23. Colborn GL, Lumsden AB, Taylor BS, Skandalakis JE. The surgical anatomy of the popliteal artery. Am Surg. 1994;60(4):238-46.

24. Gokkus K, Sagtas E, Bakalim T, Taskaya E, Aydin AT. Popliteal entrapment syndrome. A systematic review of the literature and case presentation. Muscles Ligaments Tendons J. 2014;4(2):141-8.

25. Rignault DP, Pailler JL, Lunel F. The “functional” popliteal entrapment syndrome. Int Angiol. 
1985;4(3):341-3.

26. di Marzo L, Cavallaro A. Popliteal vascular entrapment. World J Surg. 2005;29 Suppl 1:S43-5.

27. Turnipseed WD. Popliteal entrapment syndrome. J Vasc Surg. 2002;35(5):910-5.

28. Erdoes LS. Regarding "Spontaneous popliteal artery dissection: a case report and review of the literature”. J Vasc Surg. 2000;31(2):414.

29. Cohn SL, Taylor WC. Vascular problems of the lower extremity in athletes. Clin Sports Med. 1990;9(2):449-70.

30. Doral MN, Alam M, Bozkurt M, Turhan E, Atay OA, Dönmez G, et al. Functional anatomy of the Achilles tendon. Knee Surg Sports Traumatol Arthrosc. 2010;18(5):638-43.

31. Kwon YJ, Kwon TW, Um EH, Shin S, Cho YP, Kim JM, et al. Anatomical Popliteal Artery Entrapment Syndrome Caused by an Aberrant Plantaris Muscle. Vasc Specialist Int. 2015;31(3):95-101.

32. Erdoes LS, Devine JJ, Bernhard VM, Baker MR, Berman SS, Hunter GC. Popliteal vascular compression in a normal population. J Vasc Surg. 1994;20(6):978-86.

33. Turnipseed WD, Pozniak M. Popliteal entrapment as a result of neurovascular compression by the soleus and plantaris muscles. J Vasc Surg. 1992;15(2):285-93; discussion 93-4.

34. Brown CD, Muniz M, Kauvar DS. Response of the popliteal artery to treadmill exercise and stress positioning in patients with and without exertional lower extremity symptoms. J Vasc Surg. 2019;69(5):1545-51.

35. Sirico F, Palermi S, Gambardella F, Capuano E, Ferrari U, Baioccato V, et al. Ankle Brachial Index in Different Types of Popliteal Artery Entrapment Syndrome: A Systematic Review of Case Reports. J Clin Med. 2019;8(12).

36. Pillai J, Levien LJ, Haagensen M, Candy G, Cluver MD, Veller MG. Assessment of the medial head of the gastrocnemius muscle in functional compression of the popliteal artery. J Vasc Surg. 2008;48(5):1189-96.

37. Ohara N, Miyata T, Oshiro H, Shigematsu H. Surgical treatment for popliteal artery entrapment syndrome. Cardiovasc Surg. 2001;9(2):141-4.

38. di Marzo L, Cavallaro A, O’Donnell SD, Shigematsu H, Levien LJ, Rich NM, et al. Endovascular stenting for popliteal vascular entrapment is not recommended. Ann Vasc Surg. 2010;24(8):1135.e1-3.

39. Lejay A, Delay C, Georg Y, Gaertner S, Ohana M, Thaveau F, et al. Five Year Outcomes of Surgical Treatment for Popliteal Artery Entrapment Syndrome. Eur J Vasc Endovasc Surg. 2016;51(4):557-64.

40. ATKINS HJ, KEY JA. A case of myxomatous tumour arising in the adventitia of the left external iliac artery; case report. Br J Surg. 1947;34(136):426.

41. Desy NM, Spinner RJ. The etiology and management of cystic adventitial disease. J Vasc Surg. 2014;60(1):235-45, 45.e1-11.

42. Ni Mhuircheartaigh N, Kavanagh E, O’Donohoe M, Eustace S. Pseudo compartment syndrome of the calf in an athlete secondary to cystic adventitial disease of the popliteal artery. Br J Sports Med. 2005;39(9):e36.

43. Abid A, Kelley JF, Flemming DJ, Silvis ML. A young male runner with a posterior knee mass - not just your typical Baker's cyst. BMJ Case Rep. 2016;2016.

44. Peterson JJ, Kransdorf MJ, Bancroft LW, Murphey MD. Imaging characteristics of cystic adventitial disease of the peripheral arteries: presentation as soft-tissue masses. AJR Am J Roentgenol. 2003;180(3):621-5.

45. Cassar K, Engeset J. Cystic adventitial disease: a trap for the unwary. Eur J Vasc Endovasc Surg. 2005;29(1):93-6.

46. ISHIKAWA K, MISHIMA Y, KOBAYASHI S. Cystic adventitial disease of the popliteal artery. Angiology. 1961;12:357-66.

47. Ypsilantis EA, Tisi PV. Involvement of the genicular branches in cystic adventitial disease of the popliteal artery as a possible marker of unfavourable early clinical outcome: a case report. J Med 
Case Rep. 2010;4:91.

48. Baxter AR, Garg K, Lamparello PJ, Mussa FF, Cayne NS, Berland T. Cystic adventitial disease of the popliteal artery: is there a consensus in management? Vascular. 2011;19(3):163-6.

49. MAY R, THURNER J. The cause of the predominantly sinistral occurrence of thrombosis of the pelvic veins. Angiology. 1957;8(5):419-27.

50. Mickley V, Schwagierek R, Rilinger N, Görich J, Sunder-Plassmann L. Left iliac venous thrombosis caused by venous spur: treatment with thrombectomy and stent implantation. J Vasc Surg. 1998;28(3):492-7. 